Document downloaded from:

http://hdl.handle.net/10251/142679

This paper must be cited as:

Gramazio, P.; Lerma Lerma, MD.; Villanueva-Párraga, G.; Vilanova Navarro, S.; GarcíaFortea, E.; Mangino, G.; Figás-Moreno, MDR.... (09-2). Detection, molecular characterisation and aspects involving the transmission of tomato chlorotic dwarf viroid in eggplant. Annals of Applied Biology. 175(2):172-183. https://doi.org/10.1111/aab.12527

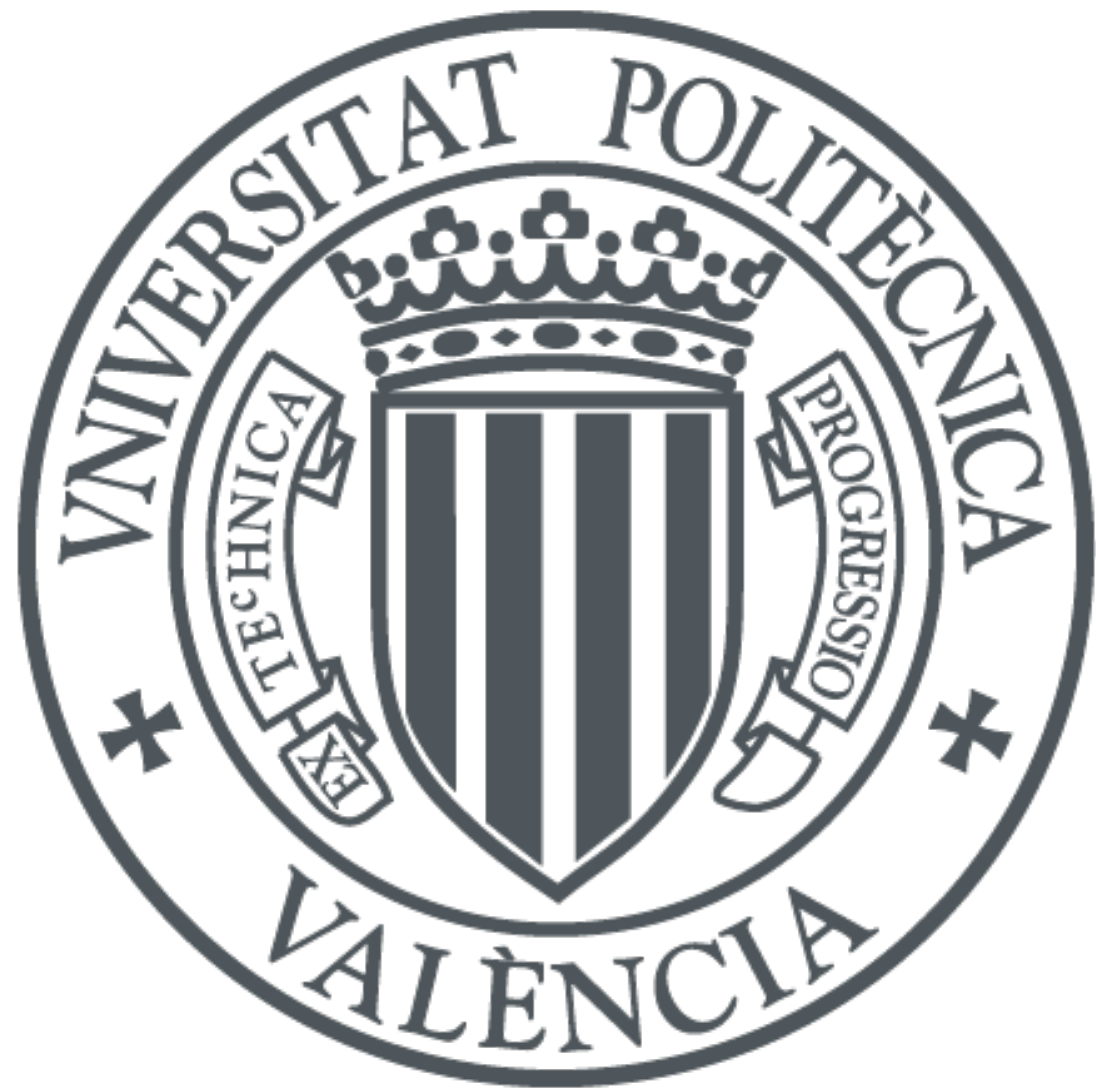

The final publication is available at

https://doi.org/10.1111/aab.12527

Copyright Blackwell Publishing

Additional Information

"This is the peer reviewed version of the following article: Gramazio P, Lerma MD, Villanueva G, et al. Detection, molecular characterisation and aspects involving the transmission of tomato chlorotic dwarf viroid in eggplant. Ann Appl Biol. 2019;175:172 183. https://doi.org/10.1111/aab.12527, which has been published in final form at https://doi.org/10.1111/aab.12527. This article may be used for non-commercial purposes in accordance with Wiley Terms and Conditions for Self-Archiving." 
Short running title: Tomato chlorotic dwarf viroid in eggplant

\section{Detection, molecular characterization and aspects involving the transmission of tomato chlorotic dwarf viroid in eggplant}

Pietro Gramazio ${ }^{1,2}$, María Dolores Lerma ${ }^{1}$, Gloria Villanueva ${ }^{1}$, Santiago Vilanova ${ }^{1}$, Edgar García-

Fortea $^{1}$, Giulio Mangino ${ }^{1}$, Maria R. Figàs ${ }^{1}$, Andrea Arrones ${ }^{1}$, David Alonso ${ }^{1}$, Alberto San Bautista $^{3}$, Salvador Soler ${ }^{1}$, Jaime Prohens ${ }^{1}$, Mariola Plazas ${ }^{1}$

${ }^{1}$ Instituto de Conservación y Mejora de la Agrodiversidad Valenciana, Universitat Politècnica de València, Camino de Vera 14, 46022 Valencia, Spain

${ }^{2}$ Faculty of Life and Environmental Sciences, University of Tsukuba, 1-1-1 Tennodai, 305-8572, Tsukuba, Japan

${ }^{3}$ Departamento de Producción Vegetal, Universitat Politècnica de València, Camino de Vera 14, 46022 Valencia, Spain

\section{Correspondence}

Mariola Plazas, Instituto de Conservación y Mejora de la Agrodiversidad Valenciana, Universitat Politècnica de València, Camino de Vera 14, 46022 Valencia, Spain.

E-mail:maplaav@btc.upv.es 


\section{SUMMARY}

Tomato chlorotic dwarf viroid (TCDVd) is a pospiviroid that causes severe disease symptoms in tomato. TCDVd is also naturally found in other crops and plants, in most occasions being asymptomatic. Apart from the natural hosts reported up to now, artificial inoculations have revealed that TCDVd can infect other plants, including eggplant (Solanum melongena). In a screening of seedlings of eggplant from a breeding programme we detected a pospiviroid, which we identified as TCDVd, representing the first report of natural infection of eggplant by TCDVd. The new TCDVd isolate of eggplant was detected by RT-PCR using primers TG21/CT20, initially designed to detect potato spindle tuber viroid (PSTVd). The new isolate sequence is close to a Brugmansia sanguinea isolate of TCDVd from the Netherlands, and most of the nucleotidic changes with respect to this isolate and to the reference genome sequence of TCDVd are found in the $T_{R}$ region. Naturally infected plants of eggplant with this TCDVd isolate did not display any disease symptoms. We demonstrated that in eggplant TCDVd is mechanically transmitted with low to moderate efficiency with cultivation practices, but not by plant-to-plant contact. Tomato plants artificially inoculated with the eggplant isolate of TCDVd tested positive for the presence of the viroid at 50 days after inoculation, but did not display any disease symptoms. Seed transmission to germinated seedlings of eggplant was variable among progenies from infected plants, ranging from $7.7 \%$ to $100.0 \%$. Disinfection of seeds with chemical treatments with sodium hypochlorite and trisodium phosphate solutions plus thermotherapy at $80^{\circ} \mathrm{C}$ for $24 \mathrm{~h}$ or $90^{\circ} \mathrm{C}$ for 6 $\mathrm{h}$ was ineffective in reducing the rate of transmission by seed. We did not find evidence of horizontal transmission of TCDVd by pollen, but vertical transmission was highly efficient when healthy eggplant plants were pollinated with infected pollen. Our results indicate that asymptomatic infection of eggplant by TCDVd and high seed and pollen transmission rates may contribute to the spread of this viroid. The information we obtained is useful in order to implement measures for the prevention, control, and eradication of TCDVd in eggplant crops, as well as to avoid their transmission to other hosts. 


\section{KEYWORDS}

mechanical transmission, pollen transmission, RT-PCR, seed disinfection, seed transmission, Solanum melongena, TCDVd, viroid sequence

\section{INTRODUCTION}

Viroids are short (239-401 nucleotides) infectious circular single-stranded RNA molecules that may be pathogenic for their hosts, which include plants of different botanical families (Flores et al., 2005; Kovalskaya \& Hammond, 2014). The over 30 viroid species described up to now are divided among families Avsunviroidae and Pospiviroidae, of which the latter is the most numerous (Di Serio et al., 2014). Depending on the viroid species and host, they have different modes of transmission, including mechanical, contact and insect transmissions, and also through grafting and vegetative reproduction tissues such as tubers, as well as by pollen and seeds (Hammond, 2017b). In addition, in some cases, insect transmission of viroids is facilitated when the viroid infected plants are coinfected by a shuttle virus, such as in the case of potato spindle tuber viroid (PSTVd) with potato leafroll virus (PLRV) (Syller et al., 1997). Viroids are of great concern in agriculture for the economic losses they can cause, which in some cases can be devastating (Hammond, 2017a; Verhoeven et al., 2017). Because of this, several viroids are included in the quarantine diseases lists in different countries (Barba \& James, 2017).

Tomato chlorotic dwarf viroid (TCDVd, Pospiviroid, Pospiviroidae), first reported 20 years ago by Singh et al. (1999) in tomato, is currently considered an emerging pathogen. TCDVd, with a length of 356-363 nucleotides, is closely related to PSTVd (Singh et al., 1999; Di Serio et al., 2014). Detection of TCDVd with RT-PCR is highly efficient and reliable (Bakker et al., 2015). In tomato, TCDVd may cause severe symptoms including plant dwarfism, top bunching, epinasty, leaf yellowing and size reduction, and fruit size reduction and deformation (Candresse et al., 2010; Fox et al., 2013; Van Bogaert et al., 2017). TCDVd, as other pospiviroids, has been frequently 
found to be naturally present in ornamental plants (James et al., 2008; Cervena et al., 2013; Candresse et al., 2017; Van Bogaert et al., 2017), which generally are asymptomatic (Shiraishi et al., 2013). TCDVd is known to be mechanically transmitted with contaminated tools (Matsushita et al., 2009; Matsuura et al., 2010b). Disinfection measures against pospiviroids include soaking and cleaning the tools used for pruning and manipulating the plants as well as the gloves used in the growing operations with solutions of several disinfectants, such as sodium hypochlorite, Virkon $^{\mathrm{TM}}$ S, or skimmed dry milk (Matsuura et al., 2010b; Li et al., 2015; Mackie et al., 2015; Ling, 2017). Also, some reports have found that TCDVd may be transmitted through seed, with a variable range of transmission to the offspring (Singh \& Dilworth, 2009; Candresse et al., 2010), while in other works no seed transmission was observed (Singh et al., 1999; Koenraadt et al., 2009; Matsushita et al., 2011; Matsushita \& Tsuda, 2016). Transmission of TCDVd by bumblebees has also been demonstrated (Matsuura et al., 2010a). Very recently, Vö et al. (2018) found that, as occurs with PSTVd, TCDVd can be transmitted by the aphid Myzus persicae when assisted by PLRV.

The rod-like structure in which pospiviroids such as TCDVd are folded is highly stable (Singh et al., 1999). In this way, it has been found that tomato crude sap from TCDVd-infected plants needs to be heated to $100^{\circ} \mathrm{C}$ for $40 \mathrm{~min}$ to inactivate the viroid (Matsushita et al., 2009). As in other pospiviroids, the secondary structure of the RNA molecule of TCDVd consists of five regions: terminal left $\left(T_{L}\right)$, pathogenic $(P)$, central $(C)$, variable $(V)$, and terminal right $\left(T_{R}\right)($ Keese \& Symons, 1985; Giguère \& Perreault, 2017). Differences in nucleotide sequence can affect pathogenicity, transmission, and host range of viroids (Wasseneger et al., 1996; Hadidi et al., 2003). In this respect, differences in the sequence of TCDVd isolates have been reported (Van Bogaert et al., 2017), which may account for differences in aggressiveness (Kovalskaya \& Hammond, 2014; Škorić, 2017; Yanagisawa et al., 2019).

Eggplant (Solanum melongena L.) is a natural host for several viroids such as PSTVd, which causes stunted growth (Minoia et al., 2015), citrus exocortis viroid (CEVd), or eggplant 
latent viroid (ELVd), although plants infected with these two latter viroids remain asymptomatic (Fagoaga \& Durán-Vila, 1996; Darós, 2017). Under experimental conditions, eggplant has also been reported as a host for TCDVd after artificial inoculation (Matsushita et al., 2009; Matsushita and Tsuda, 2016). Although this may be an indication that eggplant crops could become infected by TCDVd, to our knowledge there are no reports of outbreaks of TCDVd in eggplant crops. However, when we screened eggplant seedlings from a breeding programme for pospiviroids some of them tested positive and we subsequently identified the pospiviroid as TCDVd.

In this work, we report the first outbreak of TCDVd in eggplant and provide relevant observational and experimental information on the detection, characterization, symptomatology and transmission of TCDVd in this crop. The information obtained will be of relevance for the prevention, detection, management, and eradication of this viroid in eggplant crops and may help in devising strategies to avoid its spread.

\section{MATERIAL AND METHODS}

\subsection{Sampling, RNA extraction and TCDVd detection and characterization}

For the sampling of plantlets or adult plants of eggplant, young developing leaves were used. Typically, 3-4 disks of leaf tissue of the size of a $2 \mathrm{~mL}$ Eppendorf tube lid $(1.0 \mathrm{~cm}$ in diameter) were immediately frozen in liquid $\mathrm{N}_{2}$ and stored at $-80^{\circ} \mathrm{C}$ until used for RNA extraction. When several plants were evaluated in a bulk, the leaves were cut from the plants and stacked, and one disk of leaf tissue of each plant was taken. Pollen was extracted from flowers of individual plants by detaching the anthers and vortexing them in $2 \mathrm{~mL}$ Eppendorf tubes. Subsequently the pollen was collected by filtering it through a nylon mesh.

Total RNA was isolated using an RNA extraction kit NucleoSpin ${ }^{\circledR}$ RNA Plant (MachereyNagel, Düren, Germany) according to the manufacturer's instructions and its integrity and quality confirmed by agarose gel electrophoresis and Nanodrop ND-1000 spectrophotometer (Thermo 
Scientific, Wilmington, USA), while concentration was determined by Qubit ${ }^{\circledR} 2.0$ Fluorometer (Thermo Fisher Scientific, Waltham, USA).

Screening for pospiviroids presence was performed by RT-PCR using the primers pair TG21(F)/CT20(R), which target a 258 bp region of the PSTVd genome (Constable \& Moran, 1996). The TG21/CT20 primers pair target a conserved sequence of pospiviroids and are known to amplify several pospiviroid species other than PSTVd (Constable \& Moran, 1996). In addition, in order to identify the viroid present in the samples through the nucleotidic sequence, a set of samples that were positive with the TG21/CT20 primers were also subjected to RT-PCR using the primers pair DHL55(F)/DHL56(R), which targets a 354 bp region covering almost all the PSTVd genome (Hailstones et al., 2003). As an internal control of the RT-PCR, a 243 bp region of the highly conserved actin gene was amplified with the primer pairs ACTIN(F)/ACTIN(R), obtained from the eggplant genome sequence (Hirakawa et al., 2014). The primer sequences and amplification conditions are given as Supporting Information (Supplementary Table 1). RT-PCRs were performed in a one-step reaction using the commercial kit FastGene ${ }^{\circledR}$ IC Green One Step Mix Low-Rox (NIPPON Genetics, Tokyo, Japan) in a total volume of $10 \mu \mathrm{L}$ including $3.1 \mu \mathrm{L}$ of PCR-grade water, $5 \mu \mathrm{L}$ FastGene ${ }^{\circledR}$ IC Green One Step Mix, $0.5 \mu \mathrm{L}$ FastGene ${ }^{\circledR}$ Scriptase, $0.2 \mu \mathrm{L}$ TG21 forward primer $(10 \mu \mathrm{M}), 0.2 \mu \mathrm{L}$ CT20 reverse primer $(10 \mu \mathrm{M})$ and $1 \mu \mathrm{L}$ of template RNA (1 pg - $1 \mu \mathrm{g}$ total RNA). The PCRs were performed in an Eppendorf Mastercycler ${ }^{\circledR}$ Nexus with the following cycling protocol: reverse transcription step for one cycle at $45^{\circ} \mathrm{C}$ for $10 \mathrm{~min}$, initial denaturation step for one cycle at $95^{\circ} \mathrm{C}$ for $2 \mathrm{~min}$, followed by 40 cycles of $5 \mathrm{sec}$ at $95{ }^{\circ} \mathrm{C}$ for denaturation and of $30 \mathrm{sec}$ at $58{ }^{\circ} \mathrm{C}$ (primers pair TG21/CT20) and $55{ }^{\circ} \mathrm{C}$ (primers pair DHL55/DHL56) for annealing and elongation steps.

In order to ascertain the identity of the viroid amplified in the RT-PCR testing, three independent PCR amplification products obtained with the TG21/CT20 and DHL55/DHL56 primer pairs from three different plants from the greenhouse where the outbreak was initially detected were purified with ammonium acetate $2.5 \mathrm{M}$ and sequenced on an automatic ABI 3130XL 
sequencer (Thermo Fisher Scientific, Waltham, USA). Subsequently, a BLASTn search of the complete genome sequence of the viroid obtained was performed in the NCBI (National Center for Biotechnology Information, https://blast.ncbi.nlm.nih.gov/Blast.cgi). A multiple sequence alignment was performed using the Clustal Omega program (Sievers et al. 2011, https://www.ebi.ac.uk/Tools/msa/clustalo/), which allowed confirming the identity of the viroid (TCDVd). The eggplant TCDVd isolate sequence has been deposited at the GenBank (Accession No. MK848324). The secondary structure of the viroid was predicted using the RNAfold webserver (Gruber et al. 2008, http://rna.tbi.univie.ac.at/cgi-bin/RNAWebSuite/RNAfold.cgi).

\subsection{Evaluation of symptoms}

Plantlets and adult plants of eggplant testing positive for TCDVd, as well as siblings testing negative, were examined for symptoms of infection described in tomato, such as plant dwarfism, growth reduction, top bunching, epinasty, bronzing, leaf (in particular young ones) yellowing and curling, small and narrow leaves, and small and deformed fruits (Singh et al., 1999; Candresse et al., 2010; Singh et al., 2010; Nie, 2012; Fox et al., 2013; Van Bogaert et al., 2017). Negative testing siblings were used as controls and also examined for the same symptoms. The height of adult plants that had been naturally infected with TCDVd through seed transmission and non-infected siblings was measured in three trials when plants were six months old. Dry-skimmed milk "Pirinea" (JSP S.A., Las Palmas de Gran Canaria, Spain) at 20\% (Li et al., 2015; Mackie et al., 2015) was used as a disinfectant for pruning shears and waterproof gloves so that the blades and gloves were always soaked with the skimmed milk solution when pruning and manipulating the plants. Significance of differences between infected and non-infected plants was measured using a $t$-test at $\mathrm{p}<0.05$.

\subsection{Mechanical transmission}


In order to have an evaluation of the efficiency of natural mechanical transmission, we sampled plants from a pollinator-free greenhouse where the TCDVd outbreak was detected. This greenhouse is situated in the campus of the Universitat Politècnica de València (Valencia, Spain; GPS coordinates $39^{\circ} 29^{\prime} 01^{\prime \prime} \mathrm{N}, 0^{\circ} 20^{\prime} 27^{\prime}$ ' W; altitude $5 \mathrm{~m}$ a.s.1.). TCDVd infected plants (as determined by the positive testing of seedlings obtained from them) were known to have been present since at least 2014. The greenhouse contains 40 benches distributed in two rows of 20 benches each, which are respectively numbered from 1 to 40 (Figure 1), where up to 10 plants per bench can be grown in $15 \mathrm{~L}$ pots. Cultivation in this benched greenhouse has been uninterrupted since 2013 and plants at different growing stages have been introduced in a continuous cycle, depending on the needs of the eggplant breeding and research programmes.

The target population included 350 plants from a segregating generation obtained from non-infected seed lots and that had transferred at the plantlet stage between November 2017 and April 2018 to the greenhouse. Although this population displays genetic diversity for a number of traits, the parents of the segregating population are hosts of TCDVd, as demonstrated by their infection after artificial mechanical inoculation. Therefore, no differences in behaviour against TCDVd are expected in this population. The plants of the target population were sequentially introduced in the greenhouse with the initial aim to obtain seeds from natural selfing, and were used to evaluate natural mechanical transmission under standard greenhouse growing conditions. Among other plants in the greenhouse, there were four old ( $>1$ year) plants of different ages infected by TCDVd before the target segregating population was introduced in the greenhouse. We know that these plants were infected by TCDVd, as seed lots obtained in 2017 from the selfing of these plants (before the target segregating population was introduced in the greenhouse) were contaminated with TCDVd, as demonstrated by analysis with RT-PCR. Therefore, a natural source of inoculum was available in the greenhouse. These infected plants were distributed in benches 24 (1 plant), 27 (1 plant), and 28 (2 plants) (Figure 1). None of the plants of the target segregating 
population was pollinated with pollen from other plants, excluding pollen as potential transmission agent in this experiment.

No preventive measures for disinfecting the tools or hands were performed in the greenhouse, and the same pruning shears were used for all plants without cleaning them between plants. Pruning, trellising and plant manipulation did not follow a specific pattern and was performed depending on the needs of individual plants, although commonly all plants of the same bench were pruned and manipulated in the same day. The 350 plants of the target population were sampled in May 2018. Bulks of the 10 plants of each bench were taken and analyzed for TCDVd presence. Non-essential plants (i.e., those not selected and no longer needed in the breeding programme) from the benches that had been positive for the bulk were immediately discarded and the remaining plants were individually analyzed for TCDVd infection, totalling 65 individual plants analyzed.

The efficiency of plant-to-plant transmission was evaluated by placing at random 11 contaminated eggplant plantlets of $\mathrm{BC} 2 \mathrm{~S} 1$ (first selfing of a second backcross) generations among 37 healthy plantlets of the same generations in a plastic tunnel without pollinators. Plants were spaced at a distance of $60 \mathrm{~cm}$ within the row and $90 \mathrm{~cm}$ among rows (three rows) and were left to grow without any pruning or mechanical labour, so that as a consequence of growth their aerial parts touched the neighbour plants both within and between rows. Tissues from the initially healthy plants was tested for TCDVd five months after the transplant.

Artificial inoculation using inoculum from TCDVd infected eggplants was tested on tomato plantlets of the 'Valenciana' variety at the three true developed leaves stage. Inoculum was prepared by grinding $2 \mathrm{~g}$ of TCDVd-infected eggplant leaf tissue in $20 \mathrm{~mL}$ of $0.1 \mathrm{M}$ phosphate buffer ( $\mathrm{pH}$ 7.2) containing $25 \mathrm{mM}$ polyvinylpyrrolidone (PVP-40), 1\% active charcoal, and 1\% carborundum (600 mesh). Inoculation was performed by gently rubbing the adaxial surface of the leaves with a cotton swab soaked in the inoculum preparation. Forty plantlets were used for the experiment, of which 20 were inoculated and 20 were mock-inoculated and used as control. 
Plantlets were grown in a growth chamber under a photoperiod and temperature regime of $16 \mathrm{~h}$ light $\left(25^{\circ} \mathrm{C}\right) / 8 \mathrm{~h}$ dark $\left(18^{\circ} \mathrm{C}\right)$ until 21 days after transplant, in which three plants from the inoculated and control treatments were transferred to $1.3 \mathrm{~L}$ pots with growing substrate and placed under isolation in a greenhouse. The presence of TCDVd was tested in non-inoculated young leaves of plantlets at $7,14,21$, and in phenologically more developed plants at 50 days after inoculation.

\subsection{Seed transmission and disinfection treatments}

In order to evaluate the seed transmission of TCDVd, seed lots obtained from 14 infected plants of BC2S1 generations were germinated in seedling trays and between 16 and 30 individual seedlings per seed lot were sampled and evaluated for TCDVd infection. No chemical or physical disinfection treatments were applied to these seeds.

Additionally, seeds from the progeny of a BC2S1 individual in which plantlets had tested $100 \%$ positive for TCDVd were used for evaluating seed disinfection using chemical (external) and physical (external and internal) treatments. A total of four disinfection treatments (plus a control) were applied. For all four treatments a chemical disinfection was performed consisting of placing the seeds in a 1:10 w/v solution of dodecahydrate trisodium phosphate $\left(\mathrm{Na}_{3} \mathrm{PO}_{4} \cdot 12 \mathrm{H}_{2} \mathrm{O}\right)$ for $3 \mathrm{~h}$ and rinsing them three times with distilled water for $15 \mathrm{~min}$, followed by an additional round of disinfection with commercial bleach $(40 \mathrm{~g} / \mathrm{l}$ of $\mathrm{NaOCl})$ at $30 \%$ for 7 min and rinsing them three times with distilled water for $7 \mathrm{~min}$. After the chemical disinfection, the seeds were left to dry for several weeks on filter paper at room temperature before applying the physical disinfection treatment. The physical disinfection consisted in thermotherapy using dry heat at several temperatures at different times $\left(80^{\circ} \mathrm{C}\right.$ for $24 \mathrm{~h}, 90^{\circ} \mathrm{C}$ for $6 \mathrm{~h}, 95^{\circ} \mathrm{C}$ for $1 \mathrm{~h}$, or $100^{\circ} \mathrm{C}$ for $\left.1 \mathrm{~h}\right)$. One hundred seeds for each treatment were then germinated in Petri dishes. For the treatments where germination was obtained, 25 individual plantlets were screened for TCDVd infection. 


\subsection{Pollen transmission}

A total of 11 healthy plants of eggplant of a BC3 (third backcross) generation were grown and the first flowers were emasculated and pollinated with pollen from plants infected with TCDVd during the months of June and July 2018. The presence of TCDVd in the pollinated plants was evaluated in October 2018 after the fruits obtained after pollination with contaminated pollen were harvested. Seeds from fruits obtained after pollination with TCDVd-infected pollen were germinated, and 25 plantlets per mother plant were grown. TCDVd infection in the seedlings derived from each of the 11 mother plants was assessed in five bulks, each containing tissue of five plantlets.

\section{RESULTS}

\subsection{TCDVd detection and molecular characterization}

A number of the eggplant samples screened displayed amplified bands for the primer pair TG21/CT27 with a fragment size corresponding to the expected one (258 bp) for the presence of pospiviroids (Figure 2). Some of these positive samples were also analyzed with the primers pair DHL55/DHL56 and also tested positive, amplifying a fragment of the expected size (354 bp). The sequencing of the amplicons obtained with the DHL55/DHL56 and TG21/CT27 primer pairs resulted in a consensus nucleotidic sequence of $359 \mathrm{bp}$ from the alignment of three independent sequenced amplicons. A BLASTn search of this sequence revealed that the pospiviroid present in the samples corresponded to TCDVd, as the highest homology was obtained with TCDVd isolates from Brugmansia sanguinea detected in the Netherlands (GenBank Accession No. EF626530.1) (Verhoeven et al., 2010), with a 98.3\% (355/359) of identity. Other 18 TCDVd isolates share more than $95 \%$ of identity with our eggplant TCDVd sequence. A multiple sequence alignment was generated by comparing the sequences of the TCDVd isolate found in eggplant, the Brugmansia sanguinea isolate (EF626530.1) and the TCDVd reference genome sequence (GenBank Accession No. NC_000885.1) (Candresse et al., 2017) (Figure 3). A total of fifteen nucleotide substitutions 
and two deletions were found in the eggplant TCDVd sequence compared with the TCDVd reference sequence NC_000885.1, all of them in the right terminal domain except one nucleotide substitution in the conserved domain and another one in the pathogenic domain. There are two main changes in the $T_{R}$ domain: the sequence CGTGTAG, corresponding to the nucleotides 164 to 170, was substituted by GCAAAGA; and the sequence TTCTGCG, corresponding to the nucleotides 192 to 200, was substituted by TCTTTCGC. Two other nucleotide substitutions in the $\mathrm{T}_{\mathrm{R}}$ domain, corresponding to transitions $\mathrm{G} \rightarrow \mathrm{A}$ and $\mathrm{C} \rightarrow \mathrm{T}$, were coincident with two of the substitutions (G177A and C184T) observed in the terminal right domain loop portion in a severe isolate of TCDVd affecting potato tubers (Singh et al., 2010) (Figure 3).

The predicted secondary structure of the eggplant TCDVd genome sequence shows the typical rod-like shape present in all the members of the family Pospiviroidae (Giguère et al. 2014) (Figure 4A). Compared with the reference genome, all domains and loops are well conserved, except for a small loop located in the $\mathrm{T}_{\mathrm{R}}$ domain of the reference genome and in the Brugmansia sanguinea isolate (Figure 4B). This change is caused by the sequence substitutions mentioned above.

\subsection{Evaluation of symptoms}

Naturally infected eggplant plantlets originating from contaminated seed lots and that were positive in the RT-PCR, did not display any visible disease symptoms induced by TCDVd in tomato when compared to non-infected siblings originating from the same seed lots (Supplementary Figure 1). In addition, the observation of infected adult plants coming from this same source did not reveal any evident symptoms of disease caused by the TCDVd infection (Supplementary Figure 1). The heights of TCDVd infected plants were not significantly different ( $p>0.05$ ) from the non-infected plants in three different trials (A, B, and C) where six-month-old plants from three contaminated seed lots were grown under uniform conditions (Supplementary Table 2). 


\subsection{Mechanical transmission}

Fifteen out of the 35 bulks (42.9\%) of 10 plants ( 1 bulk per greenhouse bench) from the target population gave positive results for the presence of TCDVd (Figure 1). The distribution of benches with infected plants did not follow a random pattern, as eight out of the fifteen contaminated benches were distributed between benches 9 and 17 plus bench 30 , which is opposite to bench 11, which also gave positive results in the bulked sample (Figure 1). This group of benches is close, in the opposite row for the benches 9 to 17 and in the same row for bench 30 , to the benches containing the old contaminated plants (Figure 1). Six other benches, consisting of benches 36, 37, 39 and 40 plus benches 1 and 2 in the opposite row of benches, formed also a cluster of contaminated bulks. Finally, bench 6 was also contaminated, but in this case it was isolated (Figure 1).

Among the plants analyzed from the contaminated benches, the average percentage of contamination was of $35.4 \%$, although the range of percentage of contaminated plants among those analyzed ranged between $0 \%$ and $100 \%$, depending on the bench considered (Table 1). The fact that in some cases TCDVd was detected in the bulk of 10 plants of the bench, but not in the sample of individual plants analyzed was not surprising, as not all plants of the bench were analyzed (65 plants analyzed out of the 150 plants from contaminated benches).

Given that TCDVd was detected in 15 out of the 35 benches and that 23 out of 65 plants sampled in these benches were infected by TCDVd, the calculated percentage of infected plants in the greenhouse is $(15 / 35) \times(23 / 65) \times 100=15.2 \%$. If a random distribution of TCDVd among the plants of the target population within the greenhouse is assumed, the calculated percentage of infected plants $\left(p_{i}\right)$ would be $p_{i}=100 \times\left[1-(1-P)^{1 / \mathrm{n}}\right]$, where $P$ is the proportion of bulks where TCDVd was detected $(P=15 / 35)$ and $n$ is the number of plants per bench $(n=10)$, resulting in a value of $p i=5.4 \%$. This discrepancy of almost 3 -fold amongst the two estimates indicates that the distribution of TCDVd infected plants does not follow a random pattern in the greenhouse. In fact, 
in the main cluster of close benches where TCDVd infection was detected $(9,11,12,13,14,15$, 17 and 30), the percentage of infected plants was $47.4 \%$, while in the rest of contaminated benches $(1,2,30,36,37,39,40)$ it was only $18.5 \%$.

Regarding the evaluation of the plant-to-plant transmission in the experiment where plants were not manipulated, five months after transplant TCDVd contaminated and non-contaminated plants formed a mass of plants in which there was a high degree of contact between aerial parts of neighbouring plants within and between rows. Also, when pulling out the plants it was evident that the root systems of neighbouring plants within the row overlapped. The screening for TCDVd at the end of the experiment of the 37 initially healthy plants revealed that none of them was infected by TCDVd.

All plantlets of tomato artificially inoculated with TCDVd were negative in the RT-PCR screening for TCDVd at 7, 14, and 21 days after inoculation. However, the three inoculated plants transferred to greenhouse tested positive for TCDVd at 50 days after inoculation. No disease symptoms were observed at any of the screening dates in the inoculated plants (Supplementary Figure 2).

\subsection{Seed transmission}

The progeny of $14 \mathrm{TCDVd}$-infected plants presented a variable degree of infection with percentages ranging from $7.7 \%$ to $100.0 \%$ (Table 2), and the average value for the degree of infection in plantlets across the 14 progenies was $49.1 \%$. Significant $(\mathrm{p}<0.05)$ differences among the percentage of infection by TCDVd were detected among progenies (Table 2). Three out of the 14 progenies gave offspring with a low degree of infection, with less than $15 \%$ of plantlets infected by TCDVd, while three others had a very high degree of infection, over $95 \%$. The eight remaining progenies had a degree of infection ranging between $34.6 \%$ and $67.9 \%$ (Table 2).

\subsection{Seed disinfection}


Seeds from the control treatment and from those subjected to the chemical disinfection with trisodium phosphate and sodium hypochlorite plus thermotherapy at either $80^{\circ} \mathrm{C}$ for $24 \mathrm{~h}$ or $90^{\circ} \mathrm{C}$ for $6 \mathrm{~h}$ had high germination rates ( $\geq 94 \%$; Table 3 ). However, seeds subjected to the chemical disinfection plus thermotherapy at $95^{\circ} \mathrm{C}$ or $100^{\circ} \mathrm{C}$ for $1 \mathrm{~h}$ did not germinate. Although the radicle emerged in some seeds from the $95^{\circ} \mathrm{C}$ treatment, they did not develop to give viable plantlets. The infection rate of plantlets developing from the infected seed lot was high $(\geq 88 \%)$, and no significant differences existed among disinfection treatments and the control (Table 3).

\subsection{Pollen transmission}

TCDVd was detected in all the pollen samples obtained from TCDVd-infected plants. At least one of the flowers of each of the 11 plants that had been pollinated with pollen that tested positive for TCDVd set seeded fruit. TCDVd was not detected in any of these 11 plants after the fruits were harvested. However, 48 out of the 55 bulks of five plantlets (five bulks representing 25 plants for the offspring of each of the 11 individual plants) tested positive for TCDVd, while the other seven tested negative. Assuming a homogeneous distribution of infection among all progenies and a random distribution of infected seeds among bulks the estimated percentage of infection of individual plantlets derived from healthy plants pollinated with TCDVd-infected pollen would be, using the formula used in section 3.2, of $66.2 \%$. However, the number of positive five-plantlet bulks out of the five bulks tested per mother plant was variable, with five positive bulks for seven plants, four positive bulks for two plants, three positive bulks for one plant, and two positive bulks for one plant.

\section{DISCUSSION}

TCDVd is a pospiviroid highly related to PSTVd (Singh et al., 1999; Di Serio et al., 2014) of increasing concern, as it causes important damages in the tomato crops (Singh et al., 1999; Candresse et al., 2010; Singh et al., 2010; Nie, 2012; Fox et al., 2013; Van Bogaert et al., 2017). 
In this way, the number of reports describing its presence in tomato and other natural hosts, frequently asymptomatic ornamental plants, has dramatically raised in the last years (Matsushita et al., 2008; Ling \& Zhang, 2009; Ling et al., 2009; Candresse et al., 2010; Fox et al., 2013; Shiraishi et al., 2013; Van Bogaert et al., 2017; Verhoeven et al., 2017). In this work, we have reported for the first time the natural infection of eggplant plants by TCDVd. Although Matsushita et al. (2009) and Matsushita \& Tsuda (2016) found that eggplant was systemically infected by TCDVd after artificial inoculation, to our knowledge the natural infection of eggplant with this viroid has not been previously reported. The fact that eggplant can be a natural host for TCDVd has important implications for the control and epidemiology of this viroid.

We have found that primers pair TG21/CT20, initially designed for detecting PSTVd (Constable \& Moran, 1996), are also useful for the reliable detection of TCDVd. The 359 bp consensus sequence from three viroid genomic fragments corresponding to the whole genome allowed identifying the viroid present in the samples as TCDVd. In this way, the highest homology (>98\%) corresponded to a TCDVd from Brugmansia sanguinea from the Netherlands (Verhoeven et al., 2010), which may be an indication of the origin of the eggplant isolate. This new TCDVd isolate presented fifteen nucleotidic substitutions and two deletions compared to the tomato TCDVd reference sequence NC_000885.1, most of them in the $T_{R}$ domain. It is interesting to point out that these substitutions alter the secondary structure of the viroid, causing the loss of one of the loops in the $\mathrm{T}_{\mathrm{R}}$ domain. Other studies have also found nucleotidic differences among TCDVd isolates (Candresse et al., 2010; Van Bogaert et al., 2017). Singh et al. (2010), comparing a mutant of TCDVd inducing stunted growth and its original parental line, pointed out that the virulence determinant factor of TCDVd seems to be located in the $\mathrm{T}_{\mathrm{R}}$ domain. In this work, a severe isolate of TCDVd had several nucleotidic changes in the $\mathrm{T}_{\mathrm{R}}$ region, two of which were shared with our eggplant isolate. In other viroids, it has also been demonstrated that nucleotidic changes in specific genomic regions affect the development of symptoms, the transmission mode and efficiency, and the ability to infect specific hosts (Kovalskaya \& Hammond, 2014; Škorić, 2017; Yanagisawa et 
al., 2019). It remains to be investigated if the nucleotidic and structural changes we have observed in this TCDVd isolate have a role in any of these important aspects in eggplant.

Contrarily to what occurs in tomato, in which symptoms of TCDVd infection are severe (Singh et al., 1999; Candresse et al., 2010; Singh et al., 2010; Nie, 2012; Fox et al., 2013; Van Bogaert et al., 2017), we did not observe any symptoms caused by TCDVd infection in naturally infected plants of eggplant, even when using a genetically diverse segregating population. This indicates that, as occurs for several TCDVd ornamental hosts (Matsushita et al., 2009; Shiraishi et al., 2013; Verhoeven et al., 2017), eggplant remains asymptomatic after infection with TCDVd. While this indicates that the economic damage caused by TCDVd infection in eggplant crops is null or insignificant, the lack of symptoms also facilitates that eggplant crops act as undetected sources of infection and reservoirs of TCDVd (Verhoeven et al., 2017). On the other hand, Matsushita \& Tsuda (2015) found that eggplant plantlets artificially inoculated with TCDVd, as well as with PSTVd, tomato apical stunt viroid (TASVd), and columnea latent viroid (CLVd), presented intermittent necrosis on leaf veins after inoculation. This may suggest that this was a specific response of the eggplant genotype they used when artificially inoculated with pospiviroids.

Our results from the screenings of healthy plants introduced in a pollinator-free greenhouse where four old plants infected by TCDVd acted as sources of inoculum reveals that, as found in tomato (Verhoeven et al., 2004; Matsushita et al., 2008), mechanical transmission of TCDVd in eggplant takes place through cultivation practices. This observation is supported by the fact that the percentage of infected plants is higher than what would be expected from the results of random distribution of the disease among plants of the greenhouse, and the only potential source of transmission is mechanical. However, the relatively low percentage of infected plants among the target population indicates that the efficiency of natural mechanical transmission of TCDVd in eggplant may be lower than in tomato. In this respect, Candresse et al. (2010) found that 20 to $25 \%$ of plants within a commercial tomato greenhouse were infected with TCDVd. However, these 
authors found that the analysis of 250 bulks of 10 seeds each of the seed lot used from which the plants displaying symptoms were derived resulted in only two of the bulks infected, suggesting that seed was the original source, but that most of the plants got infected through mechanical transmission. Comparison of our data with those of Candresse et al. (2010) suggest that in eggplant the efficiency of natural mechanical transmission of TCDVd in eggplant is lower than in tomato, as the initial infection pressure was higher in our case. In any case, the transmission efficiency of TCDVd in eggplant is much lower than that of other diseases transmitted mechanically with high efficiency such as tomato mosaic virus (ToMV) in tomato (Broadbent, 1976). In this respect, our data suggest that under natural conditions the efficiency of mechanical transmission of TCDVd in eggplant is low to moderate. In fact, our results rule out plant-to-plant transmission of TCDVd due to contact of the aerial parts or through the roots. This suggests that the use of preventive measures such as the disinfection of pruning shears, tools and gloves for manipulating plants may be an efficient way to avoid TCDVd transmission in eggplant crops (Matsuura et al., 2010b; Mackie et al., 2015; Ling, 2017).

It has been demonstrated that PSTVd moves quickly within the host plants after artificial inoculation, being present in the shoot tips and young leaves as soon as 7 days after inoculation (Palukaitis, 1987). However, although tomato plants inoculated with the TCDVd eggplant isolate got infected as demonstrated by the presence of the viroid in young leaves at 50 days after inoculation, the fact that it was not detected at 21 days after inoculation or earlier indicates that the long-distance movement of this TCDVd isolate within the plant is relatively slow (Kovalskaya \& Hammond, 2014; Škorić, 2017). The lack of symptoms in tomato plantlets indicates that this isolate is asymptomatic not only in eggplant, but also in tomato.

Seed transmission is common in pospiviroids, with variable levels of transmission to the offspring having been reported (Hammond, 2017b; Škorić, 2017). In the case of TCDVd, Singh and Dilworth (2009) found that TCDVd had a high transmission rate to tomato seeds (between $26.7 \%$ and $94.4 \%$ ), while the transmission rate to the offspring in a seed lot highly contaminated 
( $86 \%$ of seed contaminated) was of $80 \%$. However, other studies reported that TCDVd was not transmitted by seed in tomato and in eggplant (Singh et al., 1999; Matsushita et al., 2011; Matsushita and Tsuda, 2016), and that TCDVd was not present in the ovules of infected tomato plants (Matsushita et al., 2011). These differences suggest that different isolate-host combinations and/or environmental conditions may affect the ability of TCDVd to be transmitted through seed. In our case, we have shown that TCDVd is naturally transmitted by seed to germinated eggplant seedlings with a high efficiency, as on average almost $50 \%$ of the plantlets originating from seeds obtained on infected plants were infected by TCDVd. This average value is similar to the one obtained by Simmons et al. (2015) and Matsushita \& Tsuda (2016) for seed transmission of PSTVd to tomato seedlings. In any case, the percentage of transmission of TCDVd to seedlings has been very variable among eggplant progenies. This wide range of variation for transmission of pospiviroids to seeds/plantlets is common (Hammond, 2017b), and are in agreement with the variable rate of infection of tomato seeds found by Singh and Dilworth (2009). Our results suggest that TCDVd contaminated eggplant seeds can be a main way for TCDVd spread. In this respect, methods based on RT-PCR are very efficient for detecting TCDVd contaminated seeds, even when only 1 in 1000 seeds is contaminated (Bakker et al., 2015). Therefore, we argue for the analysis of potentially contaminated eggplant seed lots as a way to avoid the spread of TCDVd in eggplant and other crops.

Germination of eggplant seeds from a TCDVd infected seed lot was very high. This suggests that unlike in PSTVd infected tomato seeds (Simmons et al., 2015), TCDVd infection in eggplant does not affect germination negatively. Combinations of chemical and thermotherapy treatments for seed disinfection were ineffective against TCDVd. The fact that the chemical treatments with two disinfectants, one of which (sodium hypochlorite) is highly effective against TCDVd (Matsuura et al., 2010b), did not affect transmission of TCDVd to germinated seedlings indicates that TCDVd is present in the seed embryo and/or endosperm (Singh \& Dilworth, 2009). Therefore, external disinfection of seeds with chemicals that inactivate TCDVd (Matsuura et al., 
2010b) are inefficient against this viroid. Also, given the high stability of TCDVd (Singh et al., 1999), which requires temperatures of $100^{\circ} \mathrm{C}$ for 40 min to suppress infectivity of crude sap of tomato (Matsushita et al., 2009), standard seed thermotherapy treatments at $80^{\circ} \mathrm{C}$ for $24 \mathrm{~h}$ or $90^{\circ} \mathrm{C}$ for $6 \mathrm{~h}$ for seed disinfection, which are effective against viruses such as ToMV (Prohens et al., 1999) did not result in a reduction of the rate of seed transmission. Higher temperatures, such as $95^{\circ} \mathrm{C}$ or $100^{\circ} \mathrm{C}$ for $1 \mathrm{~h}$, dramatically affected seed viability, and therefore can not be used for practical purposes.

We have detected the presence of TCDVd in pollen from infected eggplant plants, which is in agreement with results obtained with PSTVd in potato (Singh et al., 1992). However, we found no horizontal transmission in eggplant of TCDVd by pollen. Although Matsuura et al. (2010a) found that bumblebees could transmit TCDVd in tomato, these authors suggested that the horizontal transmission took place mechanically through crude sap via the bumblebee mandibles and not through pollen. Several studies performed in the related PSTVd provide contrasting results regarding horizontal transmission by pollen. In this way, while horizontal transmission of PSTVd has been demonstrated in tomato (Kryczyńsky et al., 1988) and potato (Singh et al., 1992), Yanagisawa and Matsushita (2018) found no horizontal transmission of PSTVd by pollen in petunia. Vertical transmission by PSTVd-infected pollen has been demonstrated to be very efficient in true potato seed and in petunia (Singh et al., 1992; Yanagisawa et al., 2019). Similarly, in our case, we found a high rate of vertical transmission of TCDVd in eggplant through pollen, which has important implications for the dissemination and epidemiology of this viroid in eggplant crops. However, Matsushita et al. (2011) found that TCDVd was not present in ovules of infected tomato plants before anthesis. This may suggest that transmission to seed in infected eggplant plants could be caused by pollen through the natural self-pollination mechanism of eggplant (Daunay \& Hazra, 2012), with infected pollen rather than through the infection of ovules with TCDVd from somatic tissues. Histochemical analyses of the distribution of TCDVd from infected 
plants at different stages of development, such as those performed by Matsushita et al. (2011), might shed light on the mechanism of vertical transmission of TCDVd in eggplant.

Our results from the first report of natural infection with a new TCDVd isolate in eggplant indicate that while TCDVd does not cause visible disease effects on eggplant plants and tomato plantlets, its undetected presence in this crop may facilitate its spread. The high efficiency in the transmission of TCDVd by seed to the eggplant offspring and the lack of efficiency of seed disinfection measures suggests the convenience to establish detection measures in seed lots that may have been produced in countries or areas where TCDVd is present. While in eggplant we found evidence for a low to moderate efficiency of mechanical transmission, use of preventive measures such as disinfection of tools and gloves is recommended to avoid the spread of the viroid to other plants or crops. Although we did not find evidence of horizontal transmission of TCDVd by pollen in eggplant, the fact that the vertical transmission of TCDVd to offspring through pollen in healthy mother plants is highly efficient has important implications in the management of the disease, as well as in breeding programmes, as non-infected plants can give infected offspring if fertilized with pollen from infected plants. The information obtained has been of great relevance for the containment and eradication of this outbreak. All these findings have important implications for the prevention, control, management, and eradication of TCDVd outbreaks in eggplant and their transmission to other host crops and plants.

\section{ACKNOWLEDGEMENTS}

Pietro Gramazio is grateful to Universitat Politècnica de València and to Japan Society for the Promotion of Science for their respective postdoctoral grants (PAID-10-18 and FY2019 JSPS Postdoctoral Fellowship for Research in Japan [Standard]). Andrea Arrones and David Alonso are grateful to Universitat Politècnica de València for their respective pre-doctoral (PAID-01-18 and PAID-01-16) contracts within the Programa de Ayudas de Investigación y Desarrollo initiative. Edgar García-Fortea is grateful to Ministerio de Educación, Cultura y Deporte para la Formación 
de Profesorado Universitario for a pre-doctoral grant (FPU17/02389). Giulio Mangino is grateful to Generalitat Valenciana for a pre-doctoral grant within the Santiago Grisolía programme (GRISOLIAP/2016/012). Mariola Plazas is grateful to Generalitat Valenciana and Fondo Social Europeo for a post-doctoral grant (APOSTD/2018/014).

\section{CONFLICT OF INTEREST}

The authors declare that there is no conflict of interest.

\section{REFERENCES}

Bakker, D., Bruinsma, M., Dekter, R.W., Toonen, M.A.J., Verhoeven, J.Th.J., \& Koenraadt, H.M.S. (2015). Detection of PSTVd and TCDVd in seeds of tomato using real time RTPCR. Bulletin EPPO/EPPO Bulletin, 45, 14-21.

Barba, M., \& James, D. (2017). Quarantine and certification for viroids and viroid diseases. In A. Hadidi, R. Flores, J. Randles \& P. Palukaitis (Eds.), Viroids and Satellites (pp. 415-424). London, UK: AcademicPress.

Broadbent, L. (1976). Epidemiology and control of tomato mosaic virus. Annual Review of Phytopathology, 14, 75-96.

Candresse, T., Marais, A., Tassus, X., Suhard, P., Renaudin, I., Leguay, A., Poliakoff, F., \& Blancard, D. (2010). First report of Tomato chlorotic dwarf viroid in tomato in France. Plant Disease, 94, 633.

Candresse, T. Verhoeven, J.Th.J., Stancanelli, G., Hammond, R.W., \& Winter, S. (2017). Other pospiviroids infecting solanaceous plants. In A. Hadidi, R. Flores, J. Randles \& P. Palukaitis (Eds.), Viroids and Satellites (pp. 159-168). London, UK: AcademicPress.

Cervena, G., Necekalova, J., Mikulkova, H., Levkanicova, Z., Mertelik, J., Kloudova, K., Dedic, P., \& Ptacek, J. (2011). Viroids on petunia and other solanaceous crops in the Czech Republic. Acta Horticulturae, 901, 35-40. 
Constable, F., \& Moran, J. (1996). PCR protocols for the detection of chrysanthemum stunt and potato spindle tuber viroids. Final Report for the Horticultural Research and Development Corporation, project number PT410. Victoria, Australia: Department of Natural Resources and Environment.

Darós, J.A. (2017). Eggplant latent viroid. In A. Hadidi, R. Flores, J. Randles \& P. Palukaitis (Eds.), Viroids and Satellites (pp. 339-344). London, UK: AcademicPress.

Daunay, M.C., \& Hazra, P. (2012). Eggplant. In K.V. Peter \& P. Hazra (Eds.), Handbook of Vegetables (pp. 257-322). Houston, TX, USA: Studium Press.

Di Serio, F., Flores, R., Verhoeven, J.Th.J., Li, S.F., Pallás, V., Randles, J.W., Sano, T., Vidalakis, G. \& Owens, R.A. (2014). Current status of viroid taxonomy. Archives of Virology, 159, 3467-3478.

Fagoaga, C., \& Durán-Vila, N. (1996). Naturally occurring variants of citrus exocortis viroid in vegetable crops. Plant Pathology, 45, 45-53.

Flores, R., Hernández, C., Martínez de Alba, A.E., Daròs, J.A. \& Di Serio, F. (2005). Viroids and viroid-host interactions. Annual Review of Phytopathology, 43, 117-139.

Fox, A., Daly, M., Nixon, T., Brurberg, M.B., Blystad, D.R., Harju, V., Skelton, A., \& Adams, I.P. (2013). First report of Tomato chlorotic dwarf viroid (TCDVd) in tomato in Norway and subsequent eradication. New Disease Reports, 27, 8.Giguère, T., \& Perreault, J.P. (2017). Classification of the Pospiviroidae based on their structural hallmarks. PLOS ONE, 12, e0182536.

Giguère, T., Adkar-Purushothama, C.R., \& Perreault, J.P. (2014). Comprehensive secondary structure elucidation of four genera of the family Pospiviroidae. PLOS ONE, 9, e98655.

Gruber, A.R., Lorenz, R., Bernhart, S.H., Neuböck, R., \& Hofacker, I.L. (2008). The Vienna RNA websuite. Nucleic Acids Research, 36, W70-W74. 
Hailstones, D.L., Tesoriero, L.A., Terras, M.A., \& Dephoff, C. (2003). Detection and eradication of Potato spindle tuber viroid in tomatoes in commercial production in New South Wales, Australia. Australasian Plant Pathology, 32, 317-318.

Hammond, R.W (2017a). Economic significance of viroids in vegetable and field crops. In A. Hadidi, R. Flores, J. Randles \& P. Palukaitis (Eds.), Viroids and Satellites (pp. 5-13). London, UK: AcademicPress.

Hammond, R.W (2017b). Seed, pollen, and insect transmission of viroids. In A. Hadidi, R. Flores, J. Randles \& P. Palukaitis (Eds.), Viroids and Satellites (pp. 521-530). London, UK: AcademicPress.

James, T., Mulholland, V., Jeffries, C., \& Chard, J. (2008). First report of Tomato chlorotic dwarf viroid infecting commercial petunia in the United Kingdom. Plant Pathology, 57, 400.

Keese, P., \& Symons, R.H. (1985). Domains in viroids: Evidence of intermolecular RNA rearrangements and their contribution to viroid evolution. Proceedings of the National Academy of Sciences of the USA, 82, 4582-4586.

Koenraadt, H.M.S., Jodlowska, A., Van Vliet, A., \& Verhoeven J.Th.J. (2009). Detection of TCDVd and PSTVd in seeds of tomato. Phytopathology, 99, S66.

Kovalskaya, N., \& Hammond, R.W. (2014). Molecular biology of viroid-host interactions and disease control strategies. Plant Science, 228, 48-60.

Kryczyńsky, S., Paduch-Cichal, E., \& Skrzeczkowski, L.J. (1988). Transmission of three viroids through seed and pollen of tomato plants. Journal of Phytopathology, 121, 51-57.

Li, R., Baysal-Gurel, F., Abdo, Z., Miller, S.A., \& Ling, K.S. (2015). Evaluation of disinfectants to prevent mechanical transmission of viruses and a viroid in greenhouse tomato production. Virology Journal, 12, 5.

Ling, K.S. (2017). Decontamination measures to prevent mechanical transmission of viroids. In A. Hadidi, R. Flores, J. Randles \& P. Palukaitis (Eds.), Viroids and Satellites (pp. 437445). London, UK: AcademicPress. 
Ling, K.S., \& Zhang, W. (2009). First report of natural infection by Mexican papita viroid and Tomato chlorotic dwarf viroid on greenhouse tomatoes in Mexico. Plant Disease, 93, 1216. Ling, K.S., Verhoeven, J.Th.J., Singh, R.P., \& Brown, J.K. (2009). First report of Tomato chlorotic dwarf viroid in greenhouse tomatoes in Arizona. Plant Disease, 93, 1075.

Mackie, A.E., Coutts, B.A., Barbetti, M.J., Rodoni, B.C., McKirdy, S.J., \& Jones, R.A.C. (2015). Potato spindle tuber viroid: Stability on common surfaces and inactivation with disinfectants. Plant Disease, 99, 770-775.

Matsushita, Y., \& Tsuda, S. (2015). Host ranges of Potato spindle tuber viroid, Tomato chlorotic dwarf viroid, Tomato apical stunt viroid, and Columnea latent viroid in horticultural plants. European Journal of Plant Pathology, 141, 193-197.

Matsushita, Y., \& Tsuda, S. (2016). Seed transmission of potato spindle tuber viroid, tomato chlorotic dwarf viroid, tomato apical stunt viroid, and Columnea latent viroid in horticultural plants. European Journal of Plant Pathology, 145, 1007-1011.

Matsushita, Y., Kanda, A., Usugi, T., \& Tsuda, S. (2008). First report of Tomato chlorotic dwarf viroid disease on tomato plants in Japan. Journal of General Plant Pathology, 74, 182-184.

Matsushita, Y., Usugi, T., \& Tsuda, S. (2008). First report of Tomato chlorotic dwarf viroid disease on tomato plants in Japan. Journal of General Plant Pathology, 74, 182-184.

Matsushita, Y., Usugi, T., Tsuda, S. (2009). Host range and properties of Tomato chlorotic dwarf viroid. European Journal of Plant Pathology, 124, 349-352.

Matsushita, Y., Usugi, T., Tsuda, S. (2011). Distribution of tomato chlorotic dwarf viroid in floral organs of tomato. European Journal of Plant Pathology, 130, 441-447.

Matsuura, S., Matoshita, Y., Usugi, T., Tsuda, S. (2010a). Transmission of Tomato chlorotic dwarf viroid by bumblebees (Bombus ignitus) in tomato plants. European Journal of Plant Pathology, 126, 111-115.

Matsuura, S., Matoshita, Y., Usugi, T., Tsuda, S. (2010b). Disinfection of Tomato chlorotic dwarf viroid by chemical and biological agents. Crop Protection, 29, 1157-1161. 
Minoia, S., Navarro, N., Delgado, S.; Di Serio, F., \& Flores, R. (2015). Viroid RNA turnover: characterization of the subgenomic RNAs of potato spindle tuber viroid accumulating in infected tissues provides insights into decay pathways operating in vivo. Nucleic Acids Research, 43, 2313-2325.

Nie, X. (2012). Analysis of sequence polymorphism and population structure of Tomato chlorotic dwarf viroid and Potato spindle tuber viroid in viroid-infected tomato plants. Viruses, 4, 940-953.

Palukaitis, P. (1987). Potato spindle tuber viroid: Investigation of the long-distance, intra-plant transport route. Virology, 158, 239-241.

Prohens, J., Soler, S., \& Nuez, F. (1999). The effects of thermotherapy and sodium hypochlorite treatments on pepino seed germination, a crucial step in breeding programmes. Annals of Applied Biology, 134, 299-305.

Shiraishi, T., Maejima, K., Komatsu, K., Hashimoto, M., Okano, Y., Kitazawa, Y., Yamaji, Y., \& Namba, S. (2013). First report of tomato chlorotic dwarf viroid isolated from symptomless petunia plants (Petunia spp.) in Japan. Journal of General Plant Pathology, 79, 214-216.

Sievers, F., Wilm, A., Dineen, D., Gibson, T. J., Karplus, K., Li, W., Lopez, R., McWilliam, H., Remmert, M., Söding, J., \& Thompson, J. D. (2011). Fast, scalable generation of highquality protein multiple sequence alignments using Clustal Omega. Molecular Systems Biology, 7, 539.

Simmons, H.E. Ruchti, T.B., \& Munkvold, G.P. (2015). Frequencies of seed infection and transmission to seedlings by potato spindle tuber viroid (a pospiviroid) in tomato. Journal of Plant Pathology and Microbiology, 6, 6.

Singh, R.P., \& Dilworth, A.D. (2009). Tomato chlorotic dwarf viroid in the ornamental plant Vinca minor and its transmission through tomato seed. European Journal of Plant Pathology, $123,111-116$. 
Singh, R.P., Boucher, A., \& Sommerville, T.H. (1992). Detection of Potato spindle tuber viroid in the pollen and various parts of potato plant pollinated with viroid-infected pollen. Plant Disease, 76, 951-953.

Singh, R.P., Dilworth, A.D., Ao, X., Singh, M., \& Misra, S. (2010). Molecular and biological characterization of a severe isolate of Tomato chlorotic dwarf viroid containing a novel terminal right $\left(\mathrm{T}_{\mathrm{R}}\right)$ domain sequence. European Journal of Plant Pathology, 127, 63-72.

Škorić, R.W (2017). Viroid biology. In A. Hadidi, R. Flores, J. Randles \& P. Palukaitis (Eds.), Viroids and Satellites (pp. 53-61). London, UK: AcademicPress.

Syller, J., Marczewski, W., \& Pawlowicz, J. (1997). Transmission by aphids of potato spindle tuber viroid encapsidated by potato leafroll luteovirus particles. European Journal of Plant Pathology, 123, 111-116.

Van Bogaert, N., Smagghe, G., Maes, M., De Backer, M., \& De Jonghe, K. (2017). Phylogeny of five predominant pospiviroid species in Belgium. European Journal of Plant Pathology, $149,25-33$.

Verhoeven, J.Th.J., Jansen, C.C.C., Willemen, T.M., Kox, L.F.F., Owens, R.A., \& Roenhorst, J.W. (2004). Natural infections of tomato by Citrus exocortis viroid, Columnea latent viroid, Potato spindle tuber viroid and Tomato chlorotic dwarf viroid. European Journal of Plant Pathology, 110, 823-831.

Verhoeven, J.T., Jansen, C.C., Botermans, M., \& Roenhorst, J.W. (2010), Epidemiological evidence that vegetatively propagated, solanaceous plant species act as sources of Potato spindle tuber viroid inoculum for tomato. Plant Pathology, 59, 3-12.

Verhoeven, J.Th.J., Hammond, R.W., \& Stancanelli, G. (2017). Economic significance of viroids in ornamental crops. In A. Hadidi, R. Flores, J. Randles \& P. Palukaitis (Eds.), Viroids and Satellites (pp. 27-38). London, UK: AcademicPress. 
Vö, T.T., Dehne, H.W., \& Hamacher, J. (2018). Transmission of Tomato chlorotic dwarf viroid by Myzus persicae assisted by Potato leafroll virus. Journal of Plant Diseases and Protection, 125, 259-266.

Wassenegger, M., Spieker, R.L., Thalmeir, S., Gast, F.U., Riedel, L., \& Sanger, H.L. (1996). A single nucleotide substitution converts potato spindle tuber viroid (PSTVd) from noninfectious to an infectious RNA for Nicotiana tabacum. Virology, 226, 191-197.

Yanagisawa, H., \& Matsushita, Y. (2018). Differences in dynamics of horizontal transmission of Tomato planta macho viroid and Potato spindle tuber viroid after pollination with viroidinfected pollen. Virology, 516, 258-264.

Yanagisawa, H., Sano, T., Hase, S., \& Matsushita, Y. (2019). Influence of the terminal left domain on horizontal and vertical transmissions of tomato planta macho viroid and potato spindle tuber viroid through pollen. Virology, 526, 22-31. 
Table 1. Number of analyzed and infected individual plants in the benches where TCDVd was detected in the bulk of 10 plants per bench (see Figure 1 for distribution of benches in the greenhouse). Not all plants in each bench were analyzed.

\begin{tabular}{|c|c|c|c|}
\hline Bench & Plants analyzed & Plants infected by TCDVd & TCDVd infection (\%) \\
\hline 1 & 5 & 2 & 40.0 \\
\hline 2 & 1 & 0 & 0.0 \\
\hline 6 & 5 & 1 & 20.0 \\
\hline 9 & 2 & 1 & 50.0 \\
\hline 11 & 5 & 5 & 100.0 \\
\hline 12 & 5 & 3 & 60.0 \\
\hline 13 & 8 & 2 & 25.0 \\
\hline 14 & 5 & 2 & 40.0 \\
\hline 15 & 3 & 1 & 25.0 \\
\hline 17 & 4 & 0 & 0.0 \\
\hline 30 & 6 & 4 & 67.0 \\
\hline 36 & 5 & 0 & 0.0 \\
\hline 37 & 3 & 0 & 0.0 \\
\hline 39 & 5 & 1 & 20.0 \\
\hline 40 & 3 & 1 & 33.3 \\
\hline Total & 65 & 23 & 35.4 \\
\hline
\end{tabular}


Table 2. Number of TCDVd infected and non-infected plants in progenies of 14 individual eggplant plants infected by TCDVd and degree of infection $(\%, \pm \mathrm{SE})$.

\begin{tabular}{|c|c|c|c|c|}
\hline Plant & Number of plantlets & Infected plantlets & Non-infected plantlets & $\begin{array}{c}\text { Degree of infection (\%, } \\
\qquad \mathrm{SE})\end{array}$ \\
\hline 1 & 29 & 14 & 15 & $48.3 \pm 9.3$ \\
\hline 2 & 15 & 4 & 11 & $26.7 \pm 11.4$ \\
\hline 3 & 16 & 16 & 0 & $100.0 \pm 0.0$ \\
\hline 4 & 26 & 9 & 17 & $34.6 \pm 9.3$ \\
\hline 5 & 29 & 15 & 14 & $51.7 \pm 9.3$ \\
\hline 6 & 28 & 14 & 14 & $50.0 \pm 9.4$ \\
\hline 7 & 28 & 19 & 9 & $67.9 \pm 8.8$ \\
\hline 8 & 25 & 25 & 0 & $100.0 \pm 0.0$ \\
\hline 9 & 25 & 2 & 23 & $8.0 \pm 5.4$ \\
\hline 10 & 16 & 2 & 14 & $12.5 \pm 8.3$ \\
\hline 11 & 24 & 8 & 16 & $33.3 \pm 9.6$ \\
\hline 12 & 26 & 2 & 24 & $7.7 \pm 5.2$ \\
\hline 13 & 30 & 15 & 15 & $50.0 \pm 9.1$ \\
\hline 14 & 30 & 29 & 1 & $96.7 \pm 3.3$ \\
\hline
\end{tabular}


Table 3. Germination (\%, \pm SE; based on 100 seeds) and degree of infection with TCDVd (\%; based on 25 plantlets) in a control with no disinfection treatment and after the application of four disinfection treatments consisting of a chemical treatment $(\mathrm{C}$; see text for details for the treatments) and four thermotherapy $(\mathrm{T})$ regimes using dry heat at several temperatures at different times $\left(80^{\circ} \mathrm{C}\right.$ for $24 \mathrm{~h}, 90^{\circ} \mathrm{C}$ for $6 \mathrm{~h}, 95^{\circ} \mathrm{C}$ for $1 \mathrm{~h}$, or $100^{\circ} \mathrm{C}$ for $1 \mathrm{~h}$ ).

\begin{tabular}{lcc}
\hline Treatment & Germination $(\%, \pm \mathrm{SE} ; \mathrm{n}=100)$ & TCDVd infection $(\%, \pm \mathrm{SE} ; \mathrm{n}=25)$ \\
\hline Control & $97.0 \pm 1.7$ & $88.0 \pm 6.5$ \\
$\mathrm{C}+\mathrm{T} 80^{\circ} \mathrm{C} / 24 \mathrm{~h}$ & $95.0 \pm 2.2$ & $96.0 \pm 3.9$ \\
$\mathrm{C}+\mathrm{T} 90^{\circ} \mathrm{C} / 6 \mathrm{~h}$ & $94.0 \pm 2.4$ & $96.0 \pm 3.9$ \\
$\mathrm{C}+\mathrm{T} 95^{\circ} \mathrm{C} / 1 \mathrm{~h}$ & $0.0 \pm 0.0$ & --- \\
$\mathrm{C}+\mathrm{T} 100^{\circ} \mathrm{C} / 1 \mathrm{~h}$ & $0.0 \pm 0.0$ & --- \\
\hline
\end{tabular}




\section{Figure captions}

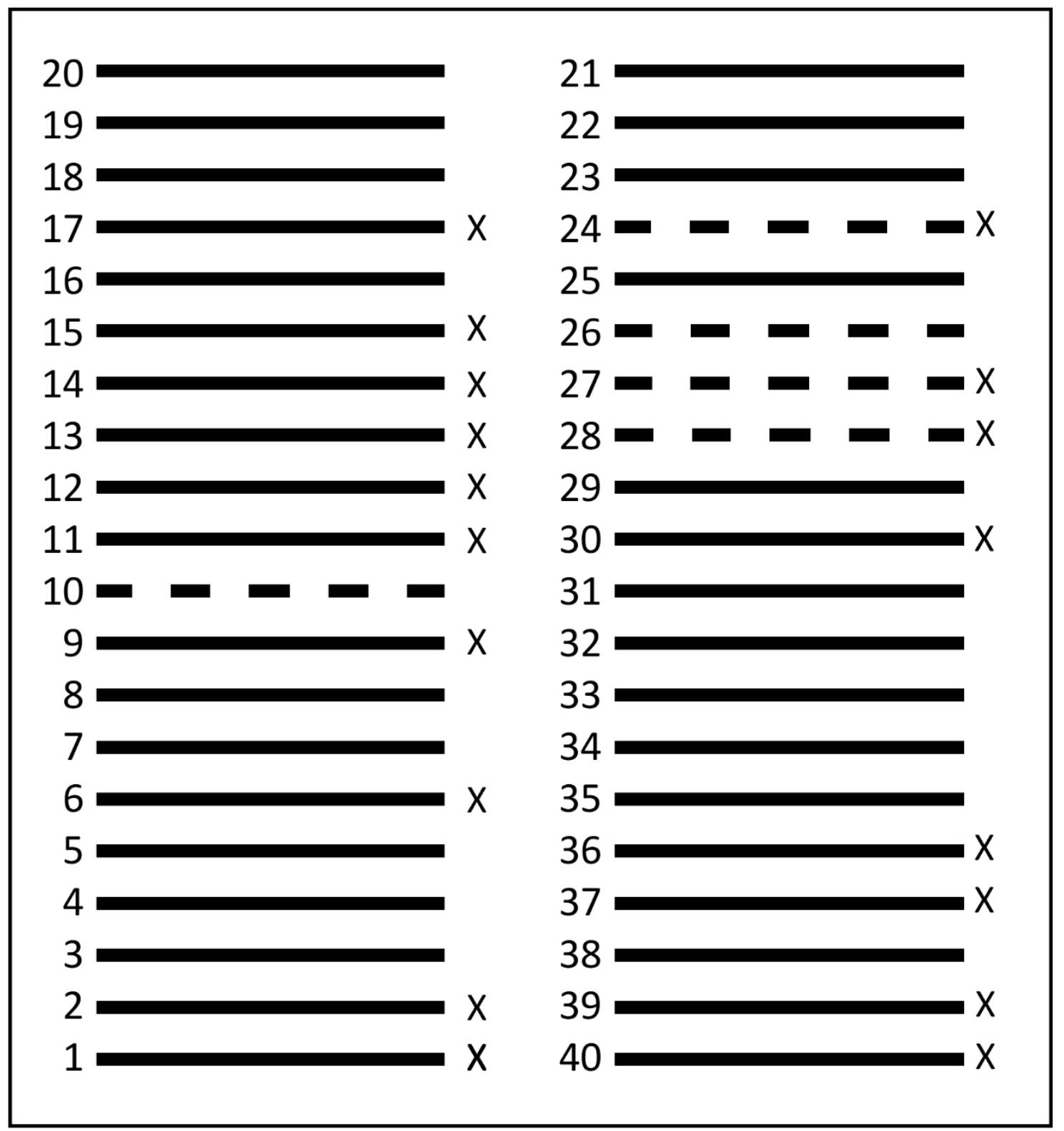

Figure 1. Distribution of eggplant plants in the greenhouse where natural transmission of TCDVd was evaluated. Each bench has a capacity of 10 potted plants. Benches in solid line were filled with non-infected plants from a segregating population of plants introduced in the greenhouse between one and six months before the sampling was performed. Benches in dashed line contained a variable number of old (>1 year) plants, including three benches (marked with an X) where one (benches 24 and 27) or two (bench 28) plants were known to be infected by TCDVd before the segregating population plants started to be introduced in the greenhouse and that served as source of inoculum. 
Benches of the segregating population where bulks of the 10 plants of the bench were positive when sampled are indicated with an X.

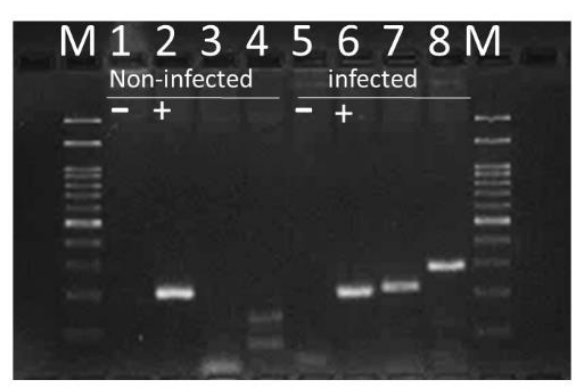

Figure 2. Detection of TCDVd in a $2 \%$ agarose gel using different primer pairs. Samples 1 to 4 represent a non-infected plant and 5 to 8 an infected plant. PCR amplification of the ACTIN mRNA was used as a positive control (samples 2 and 6) and the same primer pair without mRNA was used as a negative control (samples 1 and 5). Primer pair TG21/CT20 amplified a band in the infected plant (sample 7) but not in the non-infected plant (sample 3). A band generated by the primer pair DHL55/DHL56 was also present in the infected plant (sample 8) but not in the non-infected plant (sample 4). M indicates the 100 bp molecular weight marker lanes. 
$\mathrm{TL}$

NC_000885.1
Eggplant_TCDVd
EF626530.1
NC_000885.1
Eggplant_TCDVd
EF626530.1
NC_000885.1
Eggplant_TCDVd
EF626530.1

CGGAACTAAACTCGTGGTTCCTGTGGTTCACACCTGACCTCCTGTGCAGAAAAGAA-AAA CGGAACTAAACTCGTGGTTCCTGTGGTTCACACCTGACCTCCTGTGCAGAAAAGAAAAAA CGGAACTAAACTCGTGGTTCCTGTGGTTCACACCTGACCTCCTGTGCAGAAAAGAAAA--

P

C

AGATAGGCGGCTCGGAGGAIGCGCTTCAGGGATCCCCGGGGAAACCTGGAGCGAACTGGCA AGATAGGCGGCTCGGAGGAGCGCTTCAGGGATCCCCGGGGAAACCTGGAGCGAACTGGCA AAGAAGGCGGCTCGGAGGA GCGCTTCAGGGATCCCCGGGGAAACCTGGAGCGAACTGGCA

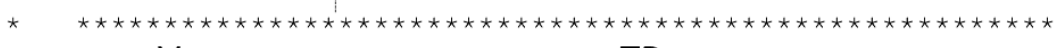
V TR

AAAGGCGGCAGGGAGCTTGTGGAAGGCGAAACAGGAGTAATCCCGTGTAGAAACAGGGTT AAAGGCGGCAGGGAGCTTGTGGAAGGCGAAACAGGAGTAATCCGCAAAGAAAC-AGGATT AAAGGCGGCAGGGAGCTTGTGGAAGGCGAAACAGGAGTAATCCGCGCAGAAAC-AGGATT

\section{TR}

\section{$\mathrm{V}$}

NC_0 00085.1

Egğplant_TCDVd EF626530.1

TTCACCCTTCCTTTCTTCTGCGGTTTCCTTCQTTTGCGCGCCACTCGACCCCTCGCCCCC TTCATCCTTCC-TTTCTTTCGCGTTTCCTTCQTTTGCGCGCCACTCGACCCCTCGCCCCC TTCATCCTTCC-TTTCT-TCGCGTTTCCTTCOTTTGCGCGCCACTCGACCCCTCGCCCCC

$\mathrm{C}$

NC_000885.1

TTGCGCTGTCGCTTCGGCAACTACCCGGTGGAAACAACTGAAGCTCCCGAGAACCGCTTT TTGCGCTGTCGCTTCGGCTACTACCCGGTGGAAACAACTGAAGCTCCCGAGAACCGCTTT TTGCGCTGTCGCTTCGGCAACTACCCGGTGGAAACAACTGAAGCTCCCGAGAACCGCTTT

Eggplant_TCDVd EF626530.1

\section{$P$}

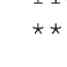

Figure 3. Multiple sequence alignment among the isolate found in eggplant (Eggplant-TCDVd; GenBank accession MK848324), the Brugmansia sanguinea isolate EF626530.1 and the reference genome NC_000885.1. The five TCDVd domains are indicated as $\mathrm{T}_{\mathrm{L}}$ (terminal left), $\mathrm{P}$ (pathogenic), $\mathrm{C}$ (central), $\mathrm{V}$ (variable) and $\mathrm{T}_{\mathrm{R}}$ (terminal right). The letters in bold font indicate nucleotidic substitutions. 
A)

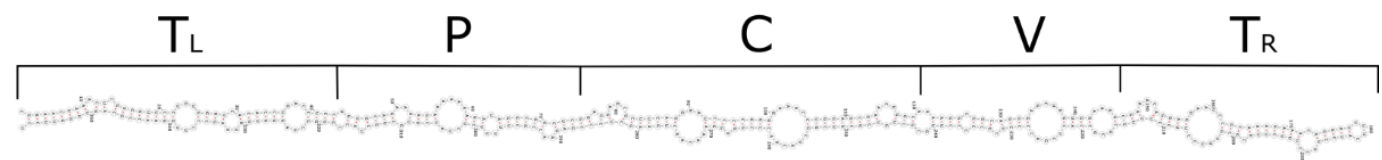

B)
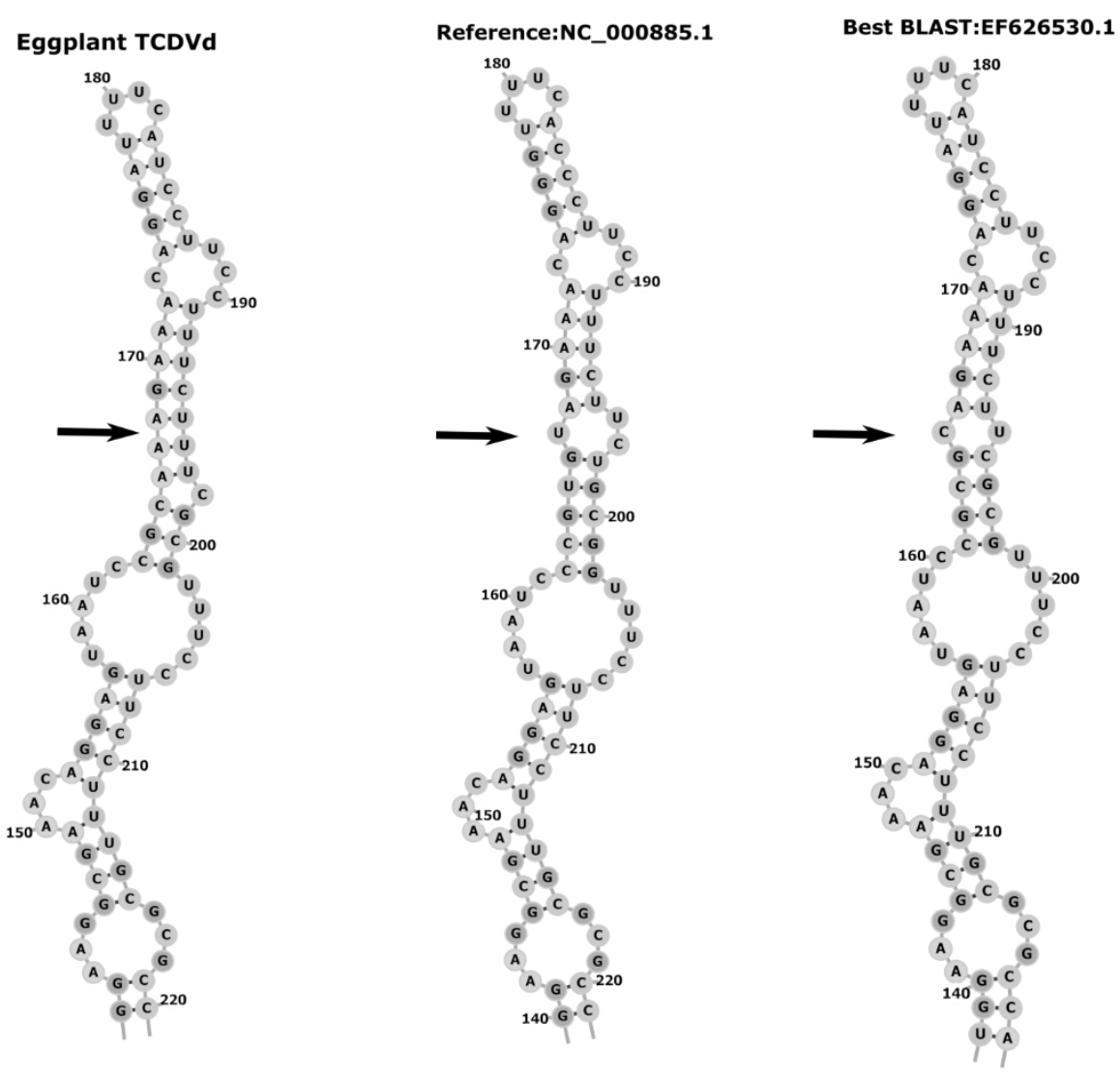

Figure 4. (A) Predicted secondary structure of the eggplant TCDVd isolate (GenBank accession MK848324). The five TCDVd domains are indicated as $\mathrm{T}_{\mathrm{L}}$ (terminal left), $\mathrm{P}$ (pathogenic), $\mathrm{C}$ (central), $\mathrm{V}$ (variable) and $\mathrm{T}_{\mathrm{R}}$ (terminal right). (B) A detailed image of the $\mathrm{T}_{\mathrm{R}}$ domain of the EggplantTCDVd isolate (accession GenBank MK848324), the Brugmansia sanguinea isolate EF626530.1 and the reference genome NC_000885.1. The arrow indicates the position of the loop that is not present in the eggplant-TCDVd isolate. 


\section{Supplementary Table captions}

Supplementary Table 1. Primer sequences used for the routine detection of TCDVd (TG21/CT20), for obtaining amplicons for sequencing covering the TCDVd genome (TG21/CT20 and DHL55/DHL56) and for the internal control of the RT-PCR (ACTIN(F)/ACTIN(R)).

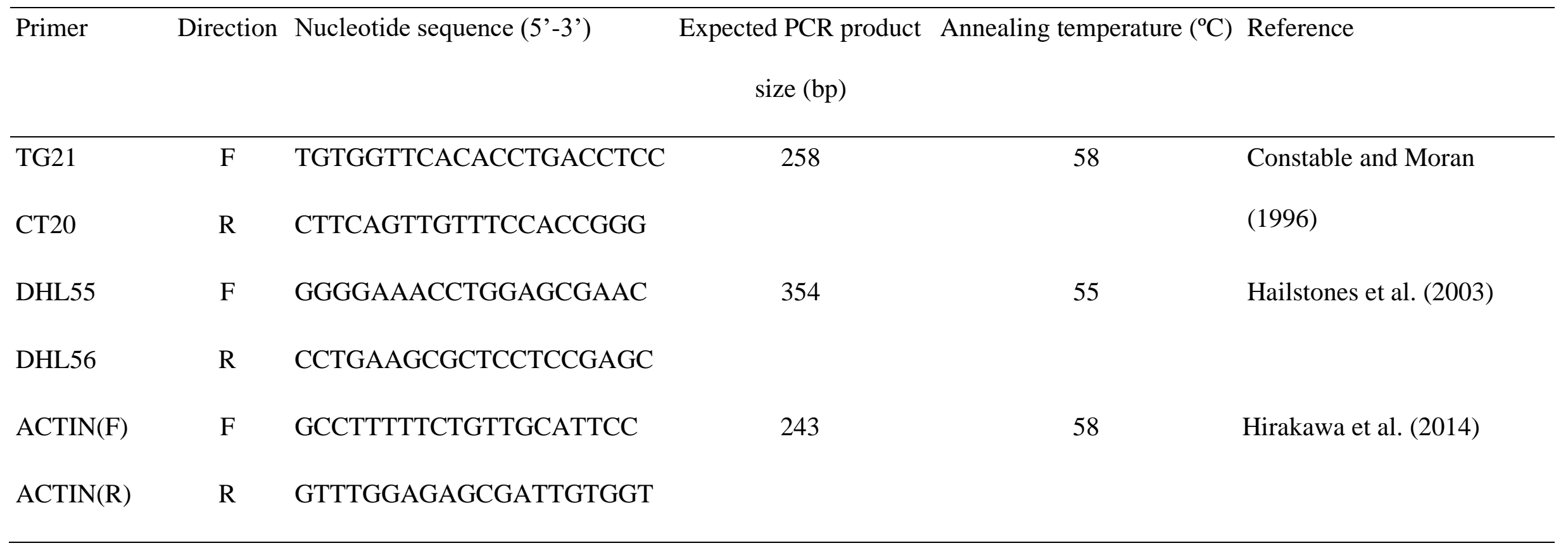


Supplementary Table 2. Comparison of plant height (average \pm SE) and significance of differences in three eggplant trials where TCDVd infected and non-infected plants derived from infected seed lots were grown.

\begin{tabular}{lcccccc}
\hline Trial & \multicolumn{2}{c}{ Infected } & & Non-infected & \multirow{2}{*}{ t-value } & Prob. $t$ \\
\cline { 2 - 5 } & $\mathrm{n}$ & Plant height $(\mathrm{cm})$ & $\mathrm{n}$ & Plant height $(\mathrm{cm})$ & & \\
\hline A & 16 & $71.4 \pm 7.1$ & 14 & $85.8 \pm 6.4$ & -1.4916 & 0.1470 \\
B & 27 & $76.4 \pm 4.4$ & 8 & $84.9 \pm 6.9$ & -0.9608 & 0.3436 \\
C & 7 & $120.5 \pm 2.7$ & 24 & $109.6 \pm 4.7$ & 1.2276 & 0.2295 \\
\hline
\end{tabular}



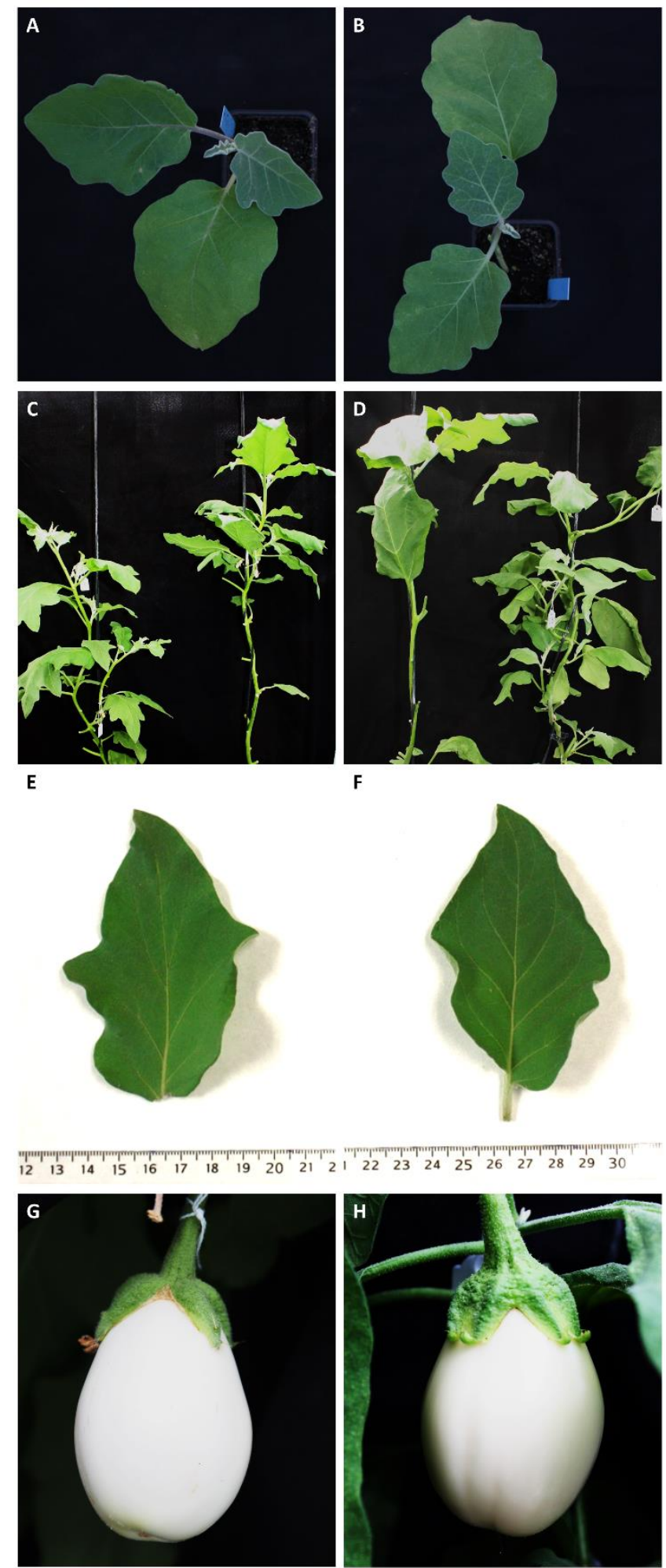

Supplementary Figure 1. Plantlets, adult plants, young leaves, and fruits of healthy (left side; A, C, E, and G) and TCDVd naturally infected by seed transmission (right side; B, D, F, and H) eggplant plants. 


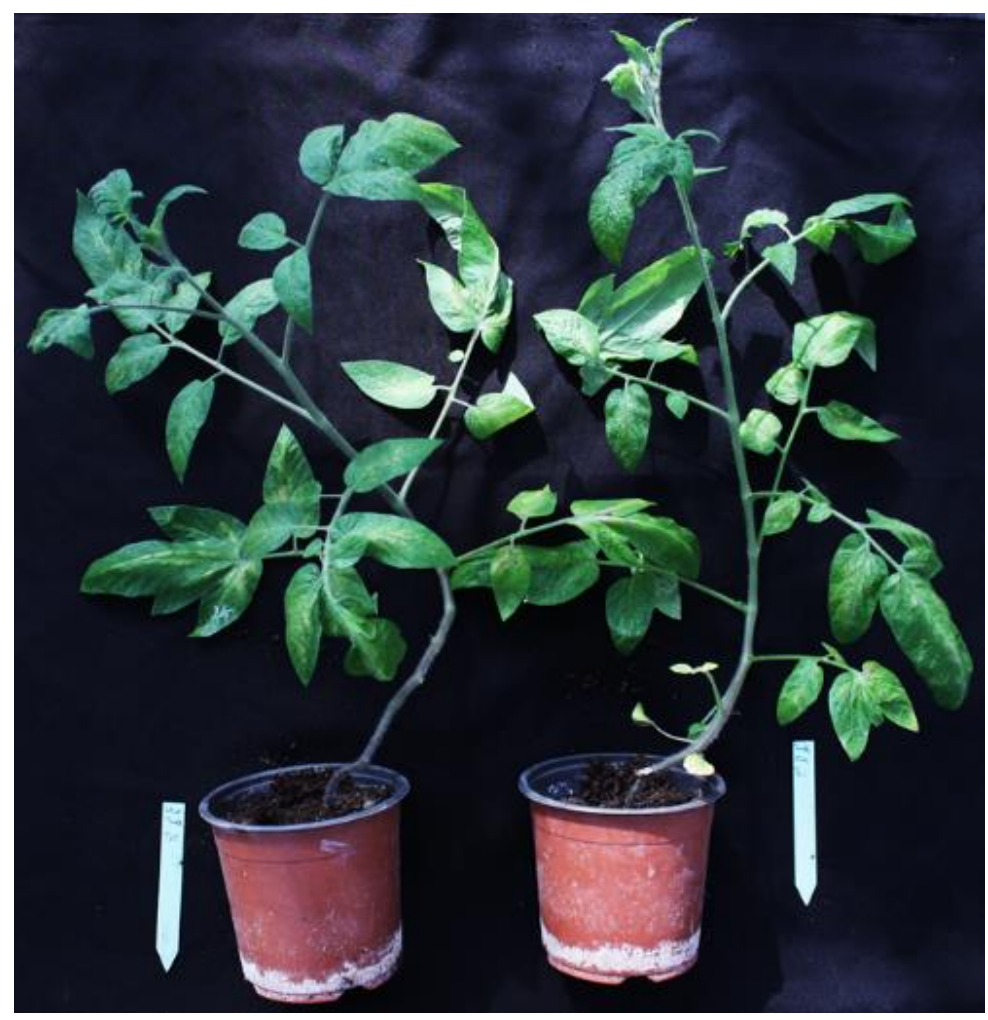

Supplementary Figure 2. Tomato plants mock-inoculated (left) and inoculated with the eggplant isolate of TCDVd (right) at 50 days after inoculation. The inoculated and mock-inoculated plants tested positive and negative, respectively, for TCDVd at 50 days after inoculation. However, both mock-inoculated and inoculated plants tested negative for TCDVd presence at 7, 14, and 21 days after inoculation. 